\title{
A new design approach for Ground Source Heat Pumps based on hourly load simulations
}

\author{
L. Lamarche ${ }^{1}$, G. Dupré ${ }^{1}$ and S. Kaj1 ${ }^{1}$ \\ ${ }^{1}$ Department of mechanical engineering \\ Ecole de Technologie Supérieure \\ 1100 Notre-Dame Ouest Montréal, CANADA H3C 1K3 \\ Phone/Fax number:1 514-396-8858/1 514-396-8530, e-mail: louis.lamarche@etsmtl.ca
}

\begin{abstract}
.
Most design programs for heat exchangers design for Groundsource heat pumps use a superposition of annual, monthly and hourly pulses. Some design methods use monthly and hourly loads. Hourly load simulations are used mostly for simulation purposes but not for design due to longer simulation time. The authors propose a new design approach based on hourly load data with the aid of an accelerated algorithm. The new approach does not use aggregation of loads and simulate the real thermal response of the individual hourly loads.
\end{abstract}

\section{Key words}

Ground-source heat pumps, Ground Heat exchanger, design algorithm, multi-year simulations, energy efficiency.

\section{Introduction}

Ground coupled heat pump (GCHP), are an important technology to achieve a very important reduction in energy consumption making the technology a safe alternative in "environment-friendly" systems. However, first cost installations slow down the market penetration for these systems especially in countries where conventional energy cost is low. In order to reduce these costs, the optimization of the length calculation is essential. Many design programs exists for design of GCHP systems [1]. However they are often based on simplified assumptions which may be correct for an over design approach but may lack precision for a real optimization. Multi year simulation tools may be required for such an approach [2]. However multi year simulations based on hourly loads are time consuming and may be used for analysis of a final design but are not appropriate for initial design purposes. Efficient algorithms were already proposed by the candidate for hourly simulations [3],[4]. In this paper, the algorithm presented in the previous papers will be applied in a overall design approach.

\section{Borehole length design}

The ASHRAE Handbook, based on the work of Kavanaugh and Rafferty [5], suggests the following relations for the length of the borehole. For cooling loads, the required length is

$$
L_{c}=\frac{q_{a} R_{g a}+\left(q_{l c}-W_{c}\right)\left(R_{b}+P L F_{m} R_{g m}+R_{g d} F_{s c}\right)}{T_{g}-\frac{T_{f i}+T_{f o}}{2}-T_{p}}
$$

where $q_{a}$, represents the annual average heat transfer to the ground. $q_{l c}$, the building cooling load. $W$ represents the power demand at design cooling loads. A similar expression is given for heating loads and the maximum length is chosen at the end. The values of $R_{g a}, R_{g m}$, and $R_{g d}$ represent effective thermal resistances for three thermal pulses: an annual pulse, a monthly pulse and a daily pulse, respectively. The periods of these pulses are generally of the order of 10 years, 1 month, and 6 hours, respectively. $R_{b}$ represents the borehole thermal resistance. $P L F m$ is the part-load factor during the design month and $F_{s c}$ represents a short-circuit heat loss due to heat transfer between the two different legs of the U-tube in the borehole. Finally, $T_{g}$ is the ground temperature, $T_{f i}, T_{f o}$, are the inlet-outlet fluid temperature and $T_{p}$, the so-called penalty temperature representing the long term interference effect. Bernier [2] propose a similar expression where a different approach is used for the calculation of the penalty temperature. The Sweden approach [6] uses a superposition of monthly and hourly loads to evaluate the length of the borehole. The borehole exit temperature is computed using equation (2)

$$
\begin{aligned}
T_{f o}=T_{g} & +\frac{q_{i}}{2 \dot{m} C_{p}}+\frac{q_{i}}{L} R_{b}+ \\
& \frac{1}{2 \pi L k} \sum_{i=1}^{N}\left(q_{i}-q_{i-1}\right) g\left(\frac{\left(t_{i}-t_{i-1}\right)}{t_{s}}, \frac{r_{b}}{L}\right)
\end{aligned}
$$

where the length $\mathrm{L}$ is iterated until the exit temperature falls within the desired design value. The summation is done on monthly periods except for the last few hours (3 or 6) where hourly loads are used. The scheme uses the concept of $g$-function developed by Eskilson [6] for the evaluation of the thermal response of the ground. A similar approach is used in the GLHEPro software proposed by Spittler [7] where the effect of the shorttime thermal response was also considered [8]. 


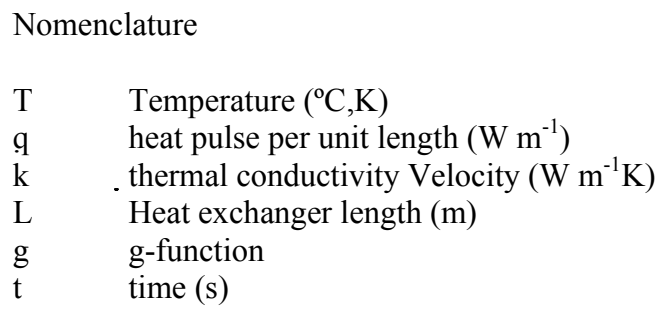

$\begin{array}{ll}\mathrm{F} & \text { recurrence coefficient } \\ \mathrm{u} & \text { transformed fonction } \\ \mathrm{Z} & \text { integration variable } \\ & \\ \text { Lower indices } \\ \mathrm{g} & \text { Ground }\end{array}$

F recurrence coefficient

$\mathrm{u}$ transformed fonction

Lower indices

g Ground
Shonder \& al [9] have made some comparisons of these different approaches for residential applications. In their comparisons, they used hourly (or less) simulations using the DST component [10] of TRNSYS as their reference values. The algorithm uses an analytical-numerical approach to simulate multi-year thermal response in a moderate CPU time. Although hourly simulations are used as "exact values", no design algorithms have been developed based on such data. The reason is that the computing time they asked is not worthwhile for preliminary design. Schemes based on aggregation of hourly loads have also been proposed [8-11] and some of these schemes were put in the form of components in simulation programs. To our knowledge, these algorithms are mostly used for simulation purposes since an iterative design procedure would require a non negligible simulation time.

\section{New scheme}

The accelerated scheme used in the new design approach is described in two previous papers $[3,4]$. Basically, the borehole temperature is computed using a recurrence formula in a form similar to:

$$
\begin{aligned}
& T_{b}(\tilde{t}+\Delta \tilde{t})-T_{g}= \\
& \frac{1}{k} \sum_{n=1}^{N} \underbrace{\left(e^{-z^{2} \Delta \tilde{t}} F_{n}(\tilde{t})+q^{\prime}(\tilde{t})\left(1-e^{-z^{2} \Delta \tilde{t}}\right) u_{n}(z)\right)}_{F_{n}(\tilde{t}+\Delta \tilde{t})} \Delta z_{n}
\end{aligned}
$$

where $\tilde{t}=\alpha t / r^{2}$ is the Fourier number, $F_{n}(\tilde{t})$ are recurrence coefficients computed from previous values as shown in (3). In the first paper [3], the scheme has been developed based on the classical cylindrical heat source function (CHS) proposed by Carslaw \& Jaegers [12]. In that case, $u_{n}(z)$ has the following analytical expression [3]:

$$
u(z)=\frac{2}{\pi^{3}} \frac{1}{z^{3}\left(J_{1}(z)^{2}+Y_{1}(z)^{2}\right)}
$$

The CHS has however limitations for long term effects and short-time thermal effects. In [4], the generalisation of the scheme has been described for any kind of thermal step response. The scheme is based on the numerically evaluation of the inverse Laplace transform.

$$
u(z)=-2 z \mathscr{L}^{-1}\left(\frac{g}{2 \pi}\right)
$$

Where $g$ is the so-called $g$-function associated with the particular bore field. Tabular values calculated by Eskilson [6] can be used. The present author proposed also an analytical solution for these functions [13] that can be used in (5). In order to evaluate the numerical efficiency of this scheme, table 1 has been taken from [3]. Comparisons are done with some aggregation schemes proposed in the past $[8,11]$

TABLE 1

CPU-time (seconds)

\begin{tabular}{|c|c|c|c|c|}
\hline \hline $\begin{array}{c}\text { Simulation } \\
\text { time }\end{array}$ & $\begin{array}{c}\text { No } \\
\text { aggregation }\end{array}$ & $\begin{array}{c}\text { New } \\
\text { scheme }\end{array}$ & Yavuzturk & Bernier \\
\hline 1 month & 16 & 0.02 & 16 & 1.7 \\
\hline 6 months & 554 & 0.1 & 135 & 7.4 \\
\hline 1 year & 2130 & 0.2 & 283 & 14 \\
\hline 5 years & 53902 & 1.1 & 1470 & 71 \\
\hline 10 years & 222830 & 1.9 & 3090 & 134 \\
\hline
\end{tabular}

In this paper we will apply the scheme for design purposes.

The design approach follows the same lines as the one proposed in the past. The total length of the ground heat exchanger will be iterated until the heat pump entrance temperatures (or the ground outlet temperatures) respect constrained design values. The difference is in the way the entrance temperatures are evaluated. The use of the new efficient scheme allow us to evaluate more precisely physical effects like short-time thermal behaviour that will give more precise evaluation of the required borehole length.

The flow chart given in fig. 1 describes the design algorithm.

We can see that two iterative loops are needed since the ground loads are not known a priori but depend on the inlet heat pump temperature. The total length is also changed in the iteration process. The simulation time is then expected to be larger than the one given in Table 1, 


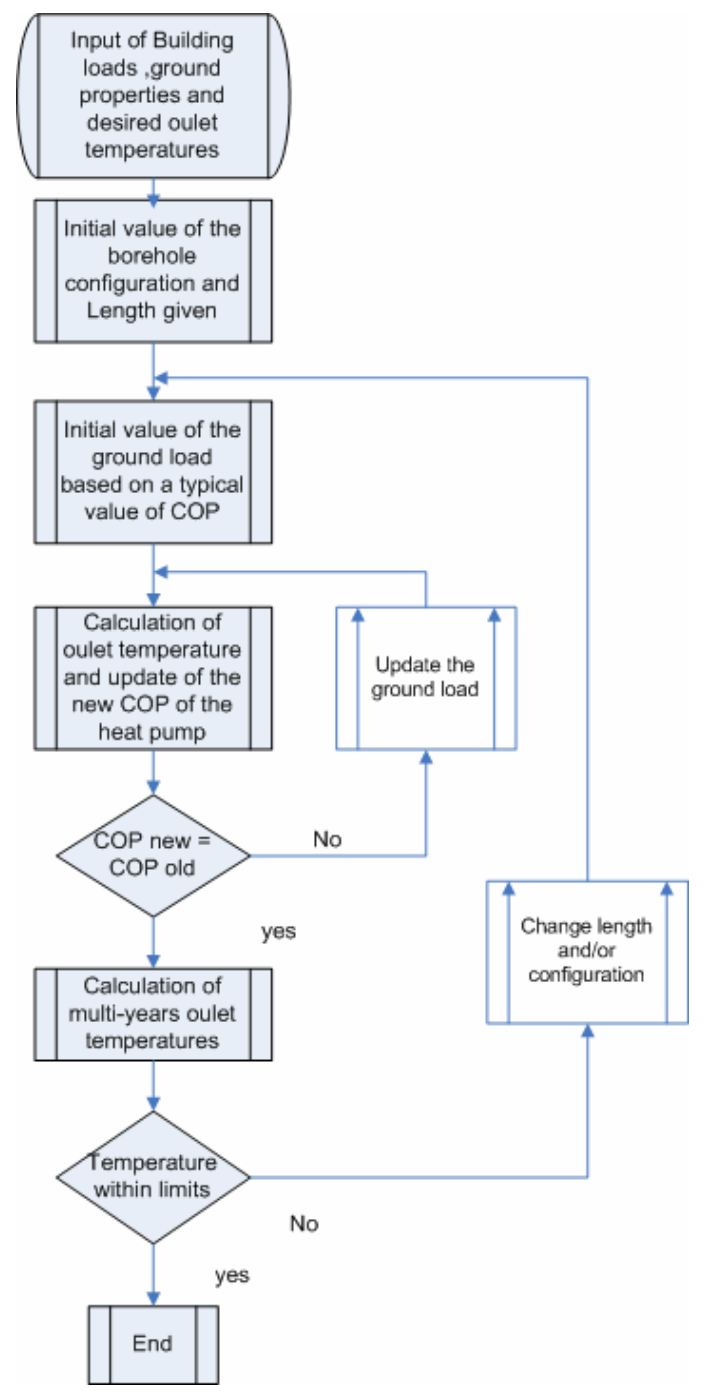

Fig. 1 Design algorithm

but they are still in an acceptable range for design purposes.

In the results section, this new scheme will be compared with 3 other methods:

- Multi year's simulation with TRNSYS. This will serve as the reference value.

- Earth Energy Designer (EED $\left.{ }^{\mathrm{TM}}\right)$ developed at Lund University.

- GS2000 ${ }^{\mathrm{TM}}$ a design software developed by the National Resource Canada.

In the following section the new scheme will be referred as the Hourly Loads Simulation Design (HLSD) scheme.

\section{Results}

The first example is based on a residential application in a northern climate (Montreal). The building loads are typical of this kind of climate, asking for a high heating demand in winter and moderate cooling during summer.
The building loads calculation were done using the TRNSYS simulation software. Fig. 2 shows the typical project in the simulation studio workspace:

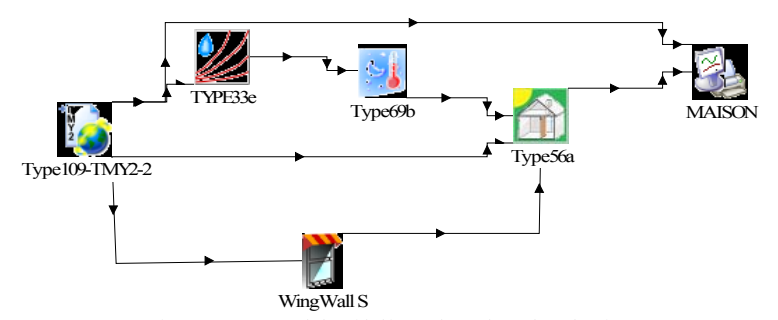

Fig. 2 annual building load calculation

The annual loads computed are shown on fig 3 .

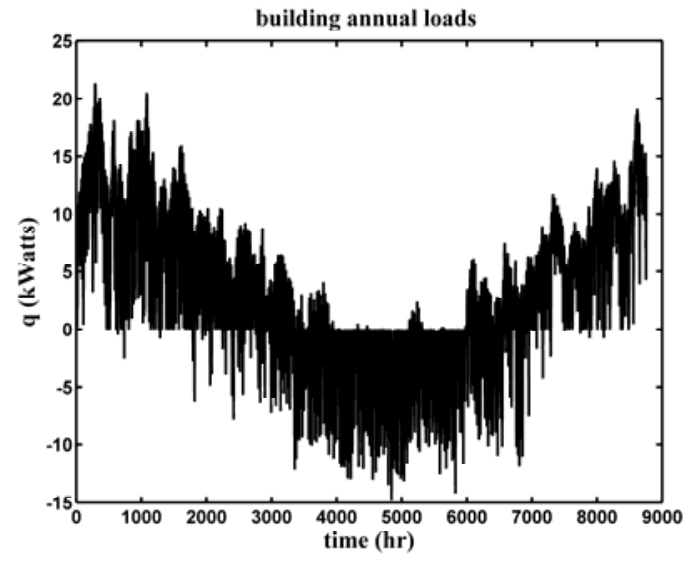

Fig. 3 annual building

In the simulation, the load was chosen large enough in order to have more than one borehole. In that case, the effect of long term thermal interference between them will be considered.

These loads were than used in another TRNSYS project which include the heat pump system, the ground coupled heat exchanger. The simulation was run during 10 years with a $0.1 \mathrm{hr}$ time step needed to insure convergence

This TRNSYS project is shown on fig. 4

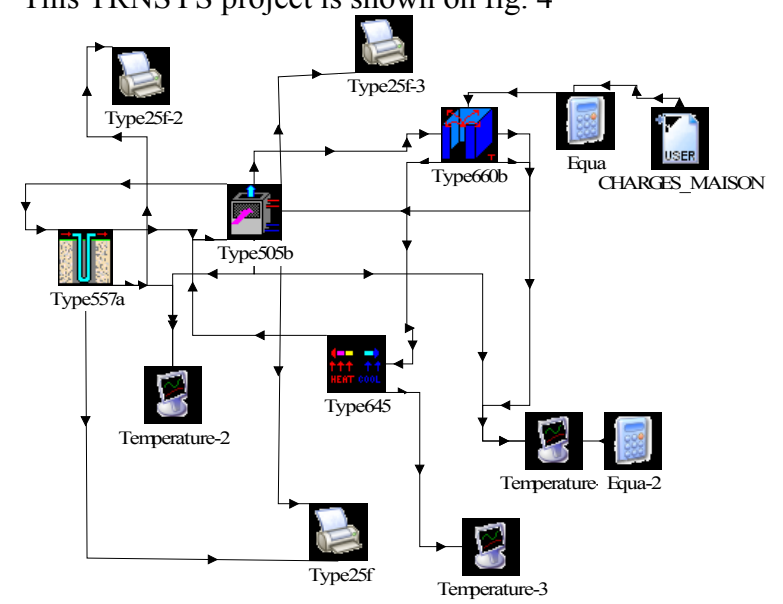

Fig. 4 multi year simulations 
Total length of the geothermal was modified until the exit ground temperature constraints were met. The following constraints were used based on the ASHRAE guidelines:

Maximum entering heat pump water teperature :

$\max \mathrm{EWT}<\mathrm{T}_{\text {ground }}+[10,15]^{\circ} \mathrm{C}$

Minimum entering heat pump water teperature :

Min EWT $>\mathrm{T}_{\text {ground }}-[5,10]^{\circ} \mathrm{C}$

$\mathrm{T}_{\text {ground }}$ was taken as $8^{\circ} \mathrm{C}$. The $\max$ EWT was fixed at 13 ${ }^{\circ} \mathrm{C}$ and $1{ }^{\circ} \mathrm{C}$ was the min EWT.

The following values summarise the input data for the borefield :

TABLE 2

Borefield configuration

\begin{tabular}{|l|l|l|}
\hline Bore diameter & $0.102 \mathrm{~m}(4$ inches $)$ & \\
\hline Tube OD & $0.034 \mathrm{~m}$ & PE8 \\
\hline Tube ID & $0.014 \mathrm{~m}$ & $125 / \mathrm{sdr} 13.5$ \\
\hline $\begin{array}{l}\text { Tube } \\
\text { conductivity }\end{array}$ & $0.4 \mathrm{~W} / \mathrm{m} \mathrm{K}$ & \\
\hline Shank spacing & $0.05 \mathrm{~m}$ & \\
\hline $\begin{array}{l}\text { Ground } \\
\text { conductivity }\end{array}$ & $1.3 \mathrm{~W} / \mathrm{m} \mathrm{K}$ & \\
\hline $\begin{array}{l}\text { Grout } \\
\text { conductivity }\end{array}$ & $1.3 \mathrm{~W} / \mathrm{m} \mathrm{K}$ & \\
\hline $\begin{array}{l}\text { Ground } \\
\text { temperature }\end{array}$ & $8^{\circ} \mathrm{C}$ & g-function \\
\hline $\begin{array}{l}\text { Temperature } \\
\text { gradient }\end{array}$ & $0{ }^{\circ} \mathrm{C} / \mathrm{m}$ & 233 in EED \\
\hline $\begin{array}{l}\text { Configuration } \\
2 \times 2 \text { rectangular } \\
5 \mathrm{~m} \text { spacing }\end{array}$ & 10 years & \\
\hline $\begin{array}{l}\text { Number of years } \\
\text { simulated }\end{array}$ & 10 & \\
\hline
\end{tabular}

The same input was used in HLSD. In the first test, the length calculations were compared with two other software programs, EED ${ }^{\mathrm{TM}}$ (Earth Energy Designer) and GS2000 ${ }^{\mathrm{TM}}$. These softwares used monthly loads. These loads were found from the hourly loads given by TRNSYS. Table 3 gives the monthly loads in MWh and table 4 gives the peak load demand needed also in the design calculation.

TABLE 3

Monthly loads (MWh)

\begin{tabular}{|l|l|l|}
\hline & Heating demand & Cooling demand \\
\hline Jan & 3.41 & 0 \\
\hline Feb & 2.64 & 0 \\
\hline Mar & 1.88 & 0 \\
\hline Apr & 0.89 & 0.079 \\
\hline May & 0.24 & 0.44 \\
\hline June & 0 & 0.897 \\
\hline Jul & 0 & 1.289 \\
\hline Aug & 0 & 0.998 \\
\hline Sep & 0.19 & 0.569 \\
\hline Oct & 0.78 & 0.207 \\
\hline
\end{tabular}

\begin{tabular}{|l|l|l|}
\hline Nov & 1.85 & 0 \\
\hline Dec & 3.1 & 0 \\
\hline
\end{tabular}

TABLE 4

Peak demand $(\mathrm{kW})$

\begin{tabular}{|l|l|l|}
\hline & Heating & Cooling \\
\hline Jan & 8.99 & 0 \\
\hline Feb & 8.67 & 0 \\
\hline Mar & 6.74 & 0 \\
\hline Apr & 4.5 & 3.46 \\
\hline May & 2.85 & 5.22 \\
\hline June & 0 & 5.72 \\
\hline Jul & 0 & 6.29 \\
\hline Aug & 0 & 6.21 \\
\hline Sep & 2.62 & 5.12 \\
\hline Oct & 3.81 & 5.05 \\
\hline Nov & 5.87 & 0 \\
\hline Dec & 8.05 & 0 \\
\hline
\end{tabular}

The total length calculation results are given in table 5 :

TABLE 5

Ground exchanger length

\begin{tabular}{|l|l|l|}
\hline GS2000 & $363 \mathrm{~m}$ & $6.8 \%$ \\
\hline EED & $358 \mathrm{~m}$ & $5.3 \%$ \\
\hline HLSD & $334 \mathrm{~m}$ & $1.7 \%$ \\
\hline Trnsys & $340 \mathrm{~m}$ & - \\
\hline
\end{tabular}

The CPU time for the 3 design programs was very small, 10 seconds or less. For TRNSYS, each 10 years simulation run took about 5 minutes. To reach the desired output temperatures, 4 to 5 runs were typically done until the constraints were met.

Fig. 5 shows the calculation of the exit temperature

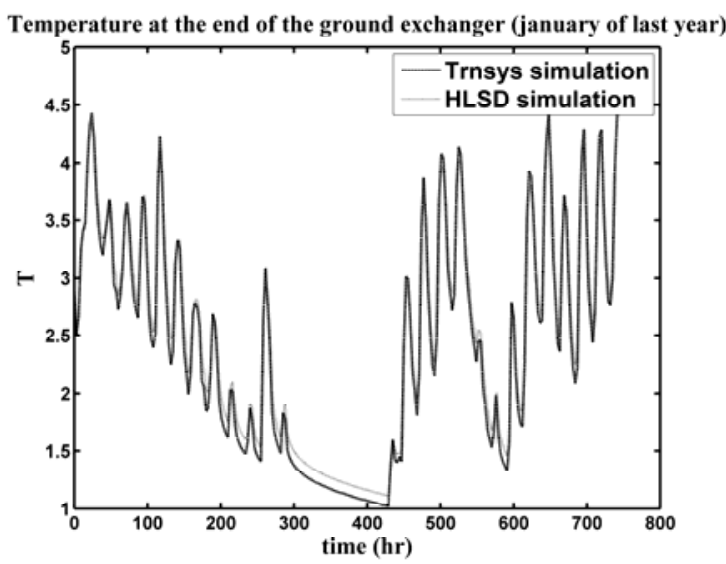

Fig. 4 Fluid temperature at the outlet of the heat exchanger

However, care should be taken with these results. The main goal here was to compare the ground model and to 
see the effect of using hourly loads versus monthly loads. For these reasons, all other parameters were fixed with those given by the TRNSYS simulation.

For exemple, the same heat pump model was used in HLSD than TRNSYS. Basically, we used the same lookup table for the COP calculations. In EED and GS2000, they use a fixed value of COP, so it was not possible to simulate the same heat pump. An average value of heating COP and cooling COP (or EER for GS2000) was then given for these softwares.

EED uses the mean fluid temperature as the input constraints to be respected instead of the output temperature. The value of $-0.55^{\circ} \mathrm{C}$ was chosen since it corresponded to the mean fluid temperature calculated in TRNSYS.

Another very important aspect was the influence of the so called "borehole resistance". This value has a very important influence in the calculation of the total heat exchanger lengh. In order to avoid large variations due to the calculation of this resistance, the value computed by TRNSYS was read and used in HLSD. In EED, it is possible to let the software compute this resistance or to give it as input. The latter configuration was chosen and the same one as in TRNSYS was given. In GS2000, it was not possible to give this value. Moreover, it is not possible to impose the grout conductivity which will influnce this value. We have to choose between some commercial known grout selection. A high conductivity grout was chosen in order to simulate the same one used in the TRNSYS simulation $(\mathrm{k}=1.3 \mathrm{~W} / \mathrm{mK})$.

Finally, a lot of different physical aspects can be modeled in the DST component of TRNSYS like pipe to pipe heat transfer in a single U-tube, ground isolation effects, ground thermal gradient, etc.. All these aspect can be added to HLSD but since they are not yet implemented, they were not considered in TRNSYS. It is not clear however if they are taken care or not in the 2 other sofwares.

\section{Conclusion}

The calculation of the total length of a ground heat exchanger is quite important since it is an important part of the initial cost. In a classical approach, the total length is computed by the superposition of multi-year heat load, a monthly load and an hourly load. Other design approaches propose the use of monthly loads superposed with a peak demand. In this paper we propose a design procedure based on hourly loads simulation for 10 to 20 years simulations. It can be argued whether it is necessary or not, but when the classical design methods are compared, hourly simulations from commercial design softwares are used. So if a quick design procedure can give the same kind of information, it is certainly a valuable tool. Some authors proposed some aggregation scheme to accelerate the evaluation of multi-year hourly simulations but these schemes still need non negligeable simulation time. In fact the design approach using monthly loads can be considered as an aggregation scheme with all aggregation blocks are months except the last few hours where the peak demand is used for the last heat pulse. Using the new nonhistory-dependent scheme, we achieve an accurate hourly calculation with a much faster scheme than the aggregation schemes giving a very powerful tool for design purposes.

\section{References}

[1] G. Hellström, B. Sanner, "PC-Programs and Modeling for Borehole Heat Exchanger Design." Proc. IGD 2001 Bad Urach, Supplement, ISS Skopje

[2] M. Bernier, M. "Closed-Loop GCHP systems", ASHRAE Journal, sept 2006 12-24.

[3] L. Lamarche, B. Beauchamp, "A Fast Algorithm for the Simulation of GCHP Systems". ASHRAE Transactions ASHRAE Transactions, 113(1), 2007, Paper DA-07-050.

[4] L. Lamarche, "A Fast Algorithm for the Simulation of GCHP Systems, part II". Submitted to Renewable Energy, June 2007

[5] S.P. Kavanaugh, K. Rafferty, Ground-Source heat pumps: Design of geothermal systems for commercial and institutional buildings, ASHRAE, Inc. Atlanta 1997.

[6] P Eskilson,, G. Thermal Analysis of Heat Extraction Boreholes. Doctoral Thesis, University of Lund, Department of Mathematical Physics. Lund, Sweden.(1987).

[7] J.D. Spitler, GLHEPRO A design tool for commercial building ground loop heat exchanger, $4^{\text {th }}$ International Conference on Heat Pumps in Cold Climates, Aylmer, Québec ,2000

[8] C. Yavusturk, J. Splitter, A short time step response factor model for vertical ground loop heat exchangers, ASHRAE Transactions 1999; 105 (2) 475.

[9] J.A. Shonder, V. Baxter, J. Thornton, P.A. Hughes, “ A new Comparison of vertical ground heat exchanger design methods for residential applications". ASHRAE Transactions 1999; SE-99-20-01

[10] D. Pahud, G. Hellstrom, "The new Duct Ground Model for TRNSYS” Eurotherm Seminar No 49, Eindhoven

[11] M. Bernier, P. Pinel, R. Labib, and R. Paillot. 2004. A multiple load aggregation for annual hourly simulations of GCHP systems, HVAC\&R Research 10(4):471-87.

[12] Carslaw, H., and J. Jaeger. 1947. Conduction of Heat in Solids.Oxford: Claremore Press

[13] L. Lamarche, B. Beauchamp, "A New Contribution to the Finite Line-source Model for Geothermal Boreholes". Energy and Buildings, 200739(2007), 188-198. 